\title{
Artigo
}

\section{Paradigmas Ambientais na Constituição Federal Brasileira de 1988}

Environmental paradigms in the Brazilian Federal Constitution of 1988

Paradigmas Ambientales en la Constitución Federal de Brasil de 1988

Sabrina Soares da Silva ${ }^{1}$ e Fernanda Santinelli ${ }^{2}$

\footnotetext{
1 Filiação institucional. Mestre e doutoranda em Administração pela Universidade Federal de Lavras. Atualmente é docente do departamento de Administração da Universidade Federal de Lavras, Lavras, MG, Brasil.

Correspondência: $\quad$ E-mail: sabrinasosil@yahoo.com.br Instituição de correspondência Universidade Federal de Lavras - Rua Nossa Senhora Aparecida, 96, Centro - Lavras - MG Brasil - CEP 37200-000
}

\begin{abstract}
2 Filiação institucional. Doutora em Filosofia do Direito e do Estado pela Pontifícia Universidade Católica de São Paulo (2008). Tem experiência na área de Direito Público com interesse de pesquisa principalmente em Direito Constitucional e Gestão Ambiental Pública. Atualmente é pesquisadora do Grupo de Pesquisa Sociedade, Estado e Gestão Pública e professora no Instituto de Ciências Sociais Aplicadas da Universidade Federal de Alfenas, Alfenas - MG - Brasil.

Correspondência:

E-mail: fernanda.santinelli@unifal-mg.edu.br Instituição de correspondência

Universidade Federal de Alfenas - Rua Gabriel Monteiro da Silva, 700 - CEP: 37130000 - Alfenas - MG - Brasil
\end{abstract}

Resumo Desde a instituição do Sistema Nacional de Unidades de Conservação da Natureza (SNUC) por meio da Lei Federal n. ${ }^{\circ}$ 9.985/2000, a gestão participativa de Unidades de Conservação (UCs), entre elas as Áreas de Proteção Ambiental (APAs), passou a ser obrigatória no Brasil. O documento determina que estas áreas devem dispor de um conselho 
presidido pelo órgão responsável por sua administração e constituído por representantes dos órgãos públicos, de organizações da sociedade civil e da população residente. Entretanto, embora o dispositivo legal determine tal perfil para a gestão destas áreas, a realidade tem se mostrado outra. Dados do Cadastro Nacional de Unidades de Conservação apontam, por exemplo, que passados 13 anos da instituição da lei, existem unidades que não constituíram conselho gestor ou elaboraram um plano de manejo, documento que orienta o uso e ocupação do território protegido. Em uma perspectiva acadêmica, a literatura acerca do tema pouco trata do processo de participação em si, sobre as dinâmicas que se dão no momento em que esta acontece, os jogos de interesses e os conflitos inerentes aos sujeitos e grupos, ou seja, sobre o processo de negociação que ocorre ao se realizar uma gestão por conselho. Diante deste cenário, o presente artigo apresenta e discute, a partir de revisão de literatura, a noção de negociação política e as práticas que a ela se relacionam, apontando caminhos para o estudo e a prática da gestão participativa de áreas de proteção.

Palavras-chave: Gestão Participativa. Negociação Política. Psicologia Política. Unidade de Conservação. Área de Proteção Ambiental (APA).

\begin{abstract}
Since the establishment of the National System of Conservation of Nature, participatory management of protected areas, including the Environmental Protection Areas, is required in Brazil. The document states that these areas should have a board chaired by the agency responsible for its administration and composed of representatives of government agencies, civil society organizations and the resident population. However, although the effect this legal device profile for the management of these areas, the reality has proved another. Data from the National Registry of Conservation of Brazil indicate, for example, that after 13 years of the institution of the law, there are units that do not constitute a board or even prepared a management plan, a document that guides the use and occupation of the territory protected. In an academic perspective, the literature rarely comes to
\end{abstract}


the participation process itself, the dynamics that occur when this happens, the games and the conflicts of interest inherent in individuals and groups, in short, on the negotiation process that occurs when performing management by the board. In this scenario, the present paper discusses, from a review of the literature, the notion of political negotiation and practices that relate to it, pointing out pathways to the study and practice of participatory management of protected areas.

Keywords: Participatory Management. Political Negotiation. Political Psychology. Conservation área. Environmental Protected Area.

Resumen Desde la institución del Sistema Nacional de Unidades de Conservación de la Naturaleza (SNUC) por medio de la Leí Federal n. ${ }^{\circ}$ 9.985/2000, la gestión participativa de Unidades de Conservación (UCS), entre ellas las Áreas de Protección Ambiental (APAs), pasó a ser obligatoria en Brasil. El documento determina que estas áreas devem disponer de un consejo presidido por el órgano responsable por su administración y constituido por representantes de los órganos públicos, de organizaciones de la sociedad civil y de la población residente. Entretanto, aún que el dispositivo legal determine tal perfil para la gestión de estas areas, la realidad se mostra otra. Datos del Catastro Nacional de Unidades de Conservación apontam, por ejemplo, que pasados 13 años de la institución de la lei, existen unidades que no constituyeron consejo gestor ó elaboraron un plan de manejo, documiento que orienta el uso y la ocupación del territorio protegido. La literatura sobre el tema poco trata del proceso de participación en sí mismo, sobre las dinámicas que ocurren en el momento en que esta acontece, los jugos de interés y los conflictos inerentes a los sujetos y grupos, o sea, sobre el proceso subjectivo y objectivo de la negociación que ocurre al se realizar una gestión por consejo. Frente a este escenario, el presente articulo presenta y discute, a partir de revisión de literatura, la noción de negociación política y las prácticas que a ella se relacionan, apuntando caminos para el estudio e la práctica de la gestión participativa del áreas de protección. Desde este punto de 
vista el articulo constituye una importante contribución para los estudios psicopolíticos en el campo ambiental.

Palabras clave: Gestión Participativa. Negociación Política. Psicología Política. Unidad de Conservación. Area de Protección Ambiental (APA). 


\section{Introdução}

Nos últimos anos, a questão ambiental vem despontando como uma das mais desafiadoras para as gerações atuais e futuras, principalmente pela constatação da gravidade e da irreversibilidade de alguns danos causados ao meio ambiente. Nesse contexto, a preocupação com a natureza conquistou amplo espaço nos âmbitos nacional e internacional, estando relacionada a praticamente todos os setores da atividade humana. Devido à abrangência dos diferentes problemas ambientais, se torna cada vez mais importante uma postura do Estado que vise preservar o ambiente e a sustentabilidade do seu uso. Toda ação estatal que tenha como finalidade a tutela do meio ambiente deve observar os princípios, direitos e deveres previstos na Constituição Federal, Lei Fundamental que, direta ou indiretamente, institui os preceitos a serem seguidos, em âmbito nacional, ao se elaborar a legislação ambiental. O processo de elaboração da Constituição é influenciado pelo sistema de crenças compartilhadas pelos indivíduos, ou seja, pelos paradigmas compartilhados em dado contexto. Os paradigmas, segundo Burrell \& Morgan (1979), constituem o sistema de ideias, crenças e valores que motivam as atitudes e a maneira como os indivíduos agem sobre o mundo. Esse termo já havia sido utilizado por Platão e Aristóteles, com o sentido de padrão ou modelo (Göktürk, s.d.), que define a maneira como vemos e acessamos o mundo, mas se tornou popular a partir de sua adoção por Kuhn (1996), para tratar da evolução da ciência. Considera-se, neste estudo, que os paradigmas constituem os princípios de organização do pensamento que governam a visão de mundo dos indivíduos e definem a lógica de seus discursos (Morin, 1990; Pirages \& Ehrlich, 1974) e que os paradigmas ambientais são aqueles que formarão a visão que se tem do ambiente e as relações estabelecidas com o mesmo.

O paradigma ambiental predominante é o antropocentrismo, que tem como base motivacional o interesse em manter a qualidade de vida, a saúde e a existência humana, tornando necessário preservar os recursos naturais e o ecossistema unicamente com esse fim. Ele justifica a relação na qual o homem preserva a natureza para seu próprio benefício. Em oposição a essa perspectiva, há o ecocentrismo, que considera a natureza como possuidora de valor intrínseco. Nessa visão, os sentimentos humanos sobre a natureza refletem a ideia de que os homens dependem da natureza e a valoram por sua própria existência. Assim, tem-se que tanto as atitudes ambientais antropocêntricas como as ecocêntricas expressam preocupação ambiental e interesse em preservar a natureza e seus recursos. Porém, os motivos desencadeadores dessa preocupação são distintos: atitudes antropocêntricas se baseiam nos efeitos que os problemas ambientais causam na humanidade, enquanto as ecocêntricas se baseiam nas consequências desses danos à própria natureza.

Em uma tentativa de superação das limitações presentes tanto na perspectiva antropocêntrica como na ecocêntrica, a sustentabilidade tem sido apontada como um novo paradigma (Gladwin, Kennelly \& Krause, 1995). O conceito de sustentabilidade, apesar de ser utilizado na biologia há algumas décadas, ganhou destaque a partir dos anos 1980, quando os problemas ambientais se tornaram mais evidentes e o nível de exploração dos recursos 
naturais se tornou preocupante. Por trás desse conceito está a busca de soluções para as questões ambientais, que tem envolvido a realização de diversas conferências e acordos internacionais, com a finalidade de limitar a ação humana sobre a natureza, o que envolve uma alteração no atual padrão de relacionamento entre os homens e entre estes e a natureza.

Nesse contexto, considera-se de grande importância que também a Constituição Federal reflita, ao menos em parte, as mudanças propostas por esse novo paradigma. Assim, esse estudo foi realizado com o objetivo de analisar a filosofia ambiental (ética ambiental) que embasou a elaboração do artigo 225 da Constituição da República Federativa do Brasil.

\section{Fundamentação Teórica}

A fundamentação teórica desse estudo foi subdividida em duas partes. Na primeira, foram apresentados os conteúdos ambientais presentes na Constituição Brasileira. Em seguida, foram discutidos os diferentes paradigmas ambientais - antropocentrismo, ecocentrismo e sustentabilidade-centrismo - e como eles determinam diferentes posicionamentos diante das questões ambientais.

\subsection{Conteúdos Ambientais na Constituição da República Federativa do} Brasil

A questão da preservação e da conservação dos recursos naturais do planeta, sob o aspecto jurídico, começou a ser abordada a partir da década de 1970. As constituições mais modernas passaram a dar-lhe tratamento explícito em seus textos, evidenciando a necessidade de uma tutela mais adequada. Serviram como fonte de inspiração ao constituinte brasileiro as constituições da Grécia (1975), de Portugal (1976) e da Espanha (1978).

Seguindo essa tendência mundial, surgiu, no ordenamento pátrio, pela primeira vez em sede constitucional, o tratamento das questões ambientais. Segundo Silva (2009), "Podese dizer que ela é uma Constituição eminentemente ambientalista. Assumiu o tratamento da matéria em termos amplos e modernos" (p. 46). Isso porque a Constituição Federal de 1988 estabelece, esparsamente ao longo do texto, os instrumentos processuais de garantia da tutela ambiental (ação popular e ação civil pública); a competência administrativa, comum, cumulativa ou paralela, atribuída em relação à União, Estados, Distrito Federal e Municípios; a competência legislativa concorrente; a função institucional do Ministério Público para a promoção do inquérito civil e o ajuizamento da ação civil pública; a defesa do meio ambiente como princípio regulador da ordem econômica e a função social ambiental da propriedade rural, dentre outros. Dois artigos que merecem destaque são os 170 e 225, por tratarem a proteção ao meio ambiente como princípio regulador da ordem econômica e da ordem social. 
O constituinte visou a harmonizar as dimensões humana e econômica do meio ambiente no artigo 170, que dispõe, in verbis (Constituição do Brasil, 1988):

Art. 170 A ordem econômica, fundada na valorização do trabalho humano e na livre iniciativa, tem por fim assegurar a todos a existência digna, conforme ditames da justiça social, observados os seguintes princípios [...]

III- defesa do meio ambiente, inclusive mediante tratamento diferenciado conforme impacto ambiental dos produtos e serviços e de seus processos de elaboração e prestação.

O núcleo do conteúdo ambiental da Constituição encontra-se no artigo 225. Alocado no título "Da Ordem Social", que tem como objetivos o bem-estar e justiça social, este artigo aponta, conforme Constituição do Brasil (1988):

Art. 225. Todos têm direito ao meio ambiente ecologicamente equilibrado, bem de uso comum do povo e essencial à sadia qualidade de vida, impondo-se ao poder público e à coletividade o dever de defendê-lo e preservá-lo para as presentes e futuras gerações.

$\S 1^{\circ}$ - Para assegurar a efetividade desse direito, incumbe ao poder público:

I - preservar e restaurar os processos ecológicos essenciais e prover o manejo ecológico das espécies e ecossistemas;

II - preservar a diversidade e a integridade do patrimônio genético do País e fiscalizar as entidades dedicadas à pesquisa e manipulação de material genético;

III - definir, em todas as unidades da Federação, espaços territoriais e seus componentes a serem especialmente protegidos, sendo a alteração e a supressão permitidas somente através de lei, vedada qualquer utilização que comprometa a integridade dos atributos que justifiquem sua proteção;

IV - exigir, na forma da lei, para instalação de obra ou atividade potencialmente causadora de significativa degradação do meio ambiente, estudo prévio de impacto ambiental, a que se dará publicidade;

V - controlar a produção, a comercialização e o emprego de técnicas, métodos e substâncias que comportem risco para a vida, a qualidade de vida e o meio ambiente; 
VI - promover a educação ambiental em todos os níveis de ensino e a conscientização pública para a preservação do meio ambiente;

VII - proteger a fauna e a flora, vedadas, na forma da lei, as práticas que coloquem em risco sua função ecológica, provoquem a extinção de espécies ou submetam os animais a crueldade.

$\S 2^{\circ}$ - Aquele que explorar recursos minerais fica obrigado a recuperar o meio ambiente degradado, de acordo com solução técnica exigida pelo órgão público competente, na forma da lei.

§ $3^{0}$ - As condutas e atividades consideradas lesivas ao meio ambiente sujeitarão os infratores, pessoas físicas ou jurídicas, a sanções penais e administrativas, independentemente da obrigação de reparar os danos causados.

§ 4ํ - A Floresta Amazônica brasileira, a Mata Atlântica, a Serra do Mar, o Pantanal Mato-Grossense e a Zona Costeira são patrimônio nacional, e sua utilização farse-á, na forma da lei, dentro de condições que assegurem a preservação do meio ambiente, inclusive quanto ao uso dos recursos naturais.

$\S 5^{\circ}$ - São indisponíveis as terras devolutas ou arrecadadas pelos Estados, por ações discriminatórias, necessárias à proteção dos ecossistemas naturais.

$\S$ 6ำ - As usinas que operem com reator nuclear deverão ter sua localização definida em lei federal, sem o que não poderão ser instaladas.

Esse dispositivo constitucional compreende, segundo Silva (2009), três espécies de normas: norma-matriz, instrumentos de garantia e determinações particulares. A norma matriz encontra-se no caput do artigo ao garantir a todos, brasileiros e estrangeiros, o direito fundamental ao meio ambiente ecologicamente equilibrado, como bem de uso comum do povo, ou seja, é bem comum, geral, difuso, indis sociável da qualidade dos seus constitutivos e, por conseguinte, indivisível, indisponível e impenhorável" (Milaré, 2011, p. 249). Assim, mesmo que seus elementos constitutivos sejam objetos de propriedade privada estes estão sujeitos ao controle da qualidade ambiental (Milaré, 2011).

Um direito que, apesar de pertencer a cada indivíduo, é de todos ao mesmo tempo e, ainda, das futuras gerações (Lenza, 2010). São dotados de um regime jurídico especial, enquanto essenciais à sadia qualidade de vida e vinculados a um fim de interesse coletivo.

Observa-se que a Constituição rompe com o modelo político do liberalismo, colocando a preservação do meio ambiente como dever do Estado e da coletividade e ainda inova ao estabelecer uma justiça distributiva entre as gerações (Derani, 2008). Assim, a utilização dos recursos naturais fica condicionada à preservação dos mesmos para as gerações futuras, de modo a possibilitar sua sadia qualidade de vida e, até mesmo, a sua reorganização éticojurídica, uma vez que "as gerações futuras podem vir a estimá-lo de modo diverso ao nosso 
(= menos antropocentricamente), inclusive conferindo-lhes a posição de sujeito de direitos" (Benjamin, 2011, p. 87).

A segunda espécie de norma, os instrumentos de garantia da efetividade do direito anunciado, está prevista no parágrafo primeiro e em seus sete incisos, nos quais são impostos, ao Poder Público, os deveres específicos. A atuação do Poder Público sai da esfera da discricionariedade administrativa para ingressar no campo da imposição, cabendo à Administração Pública proteger e preservar o meio ambiente (Milaré, 2011). São incumbências do Poder Público: (1) preservar e restaurar os processos ecológicos essenciais e prover o manejo ecológico das espécies e ecossistemas; (2) preservar a diversidade e a integridade do patrimônio genético do País e fiscalizar as entidades dedicadas à pesquisa e manipulação de material genético; (3) definir, em todas as unidades da Federação, espaços territoriais e seus componentes a serem especialmente protegidos; (4) exigir, na forma da lei, para instalação de obra ou atividade potencialmente causadora de significativa degradação do meio ambiente, estudo prévio de impacto ambiental (EIA), a que se dará publicidade; (5) controlar a produção, a comercialização e o emprego de técnicas, métodos e substâncias que comportem risco para a vida, a qualidade de vida e o meio ambiente; (6) promover a educação ambiental em todos os níveis de ensino e a conscientização pública para a preservação do meio ambiente; (7) proteger a fauna e a flora, vedadas, na forma da lei, as práticas que coloquem em risco sua função ecológica, provoquem a extinção de espécies ou submetam os animais a crueldade.

A terceira espécie normativa do artigo 225 é composta por uma série de determinações particulares que, por tratarem de áreas e situações de elevado conteúdo ecológico, mereceram a proteção constitucional. No parágrafo segundo, o constituinte obrigou aquele que explora recursos minerais a recuperar o meio ambiente degradado de acordo com solução técnica exigida pelo órgão público, por a mineração envolver bens ambientais não renováveis. Segundo o Manual do IBAMA de Recuperação de Áreas Degradadas pela Mineração, a recuperação

implica em que uma condição estável será obtida em conformidade com os valores ambientais, estéticos e sociais da circunvizinhança. Significa, também, que o sítio degradado terá condições mínimas de estabelecer um novo equilíbrio dinâmico, desenvolvendo um novo solo e uma nova paisagem (Milaré, 2011:212).

O constituinte brasileiro imputa, além das sanções civis e administrativas, sanções penais às pessoas físicas e jurídicas que praticarem condutas ou atividades lesivas ao meio ambiente.

O parágrafo terceiro trata do dano ambiental, entendido por Silva (2009) como "qualquer lesão ao meio ambiente causada por condutas ou atividades de pessoa física ou jurídica de direito público ou de direito privado" (p.302). A reparação desse dano é o ressarcimento do prejuízo causado pelo dano. Este ressarcimento pode ser feito por meio de 
indenização monetária, o que, nem sempre, é satisfatório, e pela recomposição ou reconstituição do bem degradado. No parágrafo quarto são estabelecidos como patrimônio nacional, a Floresta Amazônica, a Mata Atlântica, a serra do Mar, o pantanal mato-grossense e a zona costeira, ficando a utilização destes espaços condicionada à regulamentação legal e à preservação do meio ambiente. A expressão "patrimônio nacional" é utilizada no sentido amplo, como um valor relevante, uma riqueza e não em termos estritamente jurídicos no sentido de propriedade do Estado (Milaré, 2011).

Por fim, as terras devolutas são caracterizadas como indisponíveis e necessárias à proteção dos ecossistemas naturais (art.225, §5ํ) e as usinas que operem com reator nuclear deverão ter sua localização definida em lei federal, sem o que não poderão ser instaladas (art.225, §6º). Tendo ciência dos conteúdos ambientais previstos no artigo 225 da Constituição de 1988 passa-se à análise dos paradigmas ambientais antropocentrismo, ecocentrismo e sustentabilidade-centrismo, para, posteriormente, identificá-los no artigo ora analisado.

\subsection{Antropocentrismo, Ecocentrismo e Sustentabilidade-centrismo}

O antropocentrismo ${ }^{1}$ tem como ideia central a superioridade indiscutível do ser humano, podendo assumir duas tendências: na primeira, a natureza é vista como um recurso econômico e, na segunda, a importância da natureza é relacionada à satisfação dos múltiplos interesses humanos, não se limitando apenas aos econômicos (Campbell, 1983). Fica, assim, pressuposta uma relação na qual o homem preserva a natureza, mas, para seu próprio benefício, associado, principalmente, à manutenção da qualidade de vida humana e à sua existência (Coelho, Gouveia \& Milfont, 2006). Esse paradigma também pressupõe o progresso contínuo e a necessidade de desenvolvimento (Albrecht, Bultena, Hoiberg \& Nowak, 1982).

A natureza poderia ser vista objetivamente, sendo valorada e quantificada monetariamente (Gladwin, Kennelly \& Krause, 1995). Essa visão considera que o crescimento, a tecnologia e a ciência serão capazes de compensar a depredação dos recursos naturais e a redução dos serviços de suporte da vida, em um contínuo processo de expansão da economia global, representando o único meio de solucionar os problemas ambientais e as desigualdades sociais (Rees, 2003). A ideia de que o crescimento econômico deve ocorrer a qualquer custo termina por levar a uma série de fatores negativos, como ignorar a finitude do planeta, a tendência a acumular materiais, energia e riquezas, o desrespeito aos

\footnotetext{
1 Embora haja várias linhas teóricas que abordem o antropocentrismo, como o anthropocentrism élargi ou o weak anthropocentrism, e o econcentrismo, optou-se pela perspectiva teórica aqui apresentada, baseada principalmente em Gladwin, Kennellye Krause (1995), visto não ser objetivo desse estudo analisar es sas diferentes perspectivas teóricas.
} 
limites biofísicos e a destruição dos sistemas de sustentação da vida (Rohde, 1998).

Embora se reconheça que os pressupostos desse paradigma possam legitimar a destruição ambiental, ela continua sendo a perspectiva predominante, mesmo que outras visões se oponham a ela, como o ecocentrismo, que defende o valor não instrumental dos ecossistemas e da ecosfera, cujo equilibrio seria limitante a determinadas atividades humanas. Assume-se que a natureza, assim como qualquer ser que nela exista, tem um valor além daquele associado à sua utilidade para os homens. $O$ funcionamento da economia dependeria da energia e da matéria disponibilizadas pela ecosfera, governada pela segunda lei da termodinâmica, pela qual a natureza seria a produtora e a economia a consumidora, ou seja, a economia requer um fluxo contínuo de entrada de energia e matéria proveniente da natureza para sustentar a produção de bens e serviços (Rees, 2003).

Como paradigmas opostos, o antropocentrismo e o ecocentrismo parecem estar em um estado de mútuo desprezo e negação. Ambos acabam por receberem críticas por não preverem a conservação da natureza ou o desenvolvimento social. A noção de uma perspectiva centrada na sustentabilidade pode ser compreendida como um crescimento dialético nesta disputa, representando uma síntese que busca uma maior e mais profunda integração entre as ideias antropocêntricas e ecocêntricas (Gladwin, Kennelly \& Krause, 1995). A sustentabilidade estaria associada a princípios de austeridade, sobriedade e simplicidade, de forma que sejam respeitados os limites impostos pela disponibilidade de recursos ambientais. Esta seria a única maneira de se minimizar a ação da segunda lei da termodinâmica no processo econômico, com sua inevitável degradação entrópica. Estaria vinculada também ao reconhecimento de que os seres humanos têm necessidades que vão além da subsistência e que a diversidade cultural deve ser respeitada. Dever-se-iam buscar, continuamente, condições iguais ou superiores de vida para um grupo de pessoas e seus sucessores, de modo que o meio ambiente fosse menos perceptivelmente degradado. A sustentabilidade estaria ligada à ideia de manutenção de nosso sistema de suporte da vida, mas procurando obedecer às leis da natureza (Cavalcanti, 1998).

Redclift (2005) defende que os sistemas ecológicos e o ambiente devem ser considerados como passíveis de serem administrados pelo Estado e organizações internacionais. Isso representa uma grande mudança desde o princípio da soberania, pois o paradigma da sustentabilidade considera que 0 Estado deve assumir responsabilidades compartilhadas pelo ambiente e pela humanidade. A natureza, em essência, deve ser vista como condição primária das atividades humanas, que permeia tudo o que o homem faz e pretende fazer, determinando suas possibilidades (Cavalcanti, 1998). Essa mudança de perspectiva alteraria a visão que a humanidade tem da natureza, pois esta não poderia mais ser vista apenas como provedora de recursos e destino dos resíduos dos processos produtivos. Adotar a perspectiva da sustentabilidade-centrismo deve partir da ideia de que homem e natureza estão integrados. 


\section{Método de Pesquisa}

Esse estudo qualitativo, de natureza descritiva, teve como objeto o artigo 225, núcleo da temática ambiental na Constituição Federativa de 1988. Foi feita uma análise de conteúdo, dividida em três fases distintas, conforme sugerido por Bardin (1979): pré-análise, exploração do material e tratamento dos resultados obtidos, inferência e interpretação. Inicialmente, foi feita uma leitura do material e uma organização primária do mesmo, definindo-se quais os principais pressupostos dos três paradigmas ambientais - antropocentrismo, ecocentrismo e sustentabilidade-centrismo - e como eles poderiam ser identificados no texto constitucional.

Tendo ciência de que interpretação constitucional, não se resolve apenas com a invocação da norma, faz-se necessário encontrar regras para a determinação do sentido dos seus signos linguísticos (Ferraz, 2003). As dificuldades para a "operação de determinação" semântica das normas constitucionais são apontadas por Canotilho (1998): os plurissignificados de seus elementos linguísticos, os conceitos de valor muitas vezes utilizados e os conceitos de prognose, ou antecipação de consequências futuras, que se encontram nos preceitos constitucionais. Essas características tornam complicada a investigação do conteúdo semântico das normas constitucionais, porém, não a inviabilizam. A linguagem pode ter tantos planos de superfície como de profundidade. A distinção se faz quando se analisa o modo em que determinada palavra foi utilizada e o sentido que se quis dar a ela.

Há dois eixos que perpassam esses planos: o diacrônico, que permite a transmissão de uma língua através do tempo e das gerações, sofrendo, neste transcurso, mudanças fonéticas, mórficas, sintáticas, semânticas e léxicas; e o sincrônico, que é o estudo da língua em que se faz a abstração do tempo, estudando apenas seu significado presente (Gonçalves, 2002). Estes dois eixos têm uma inter-relação com os três planos semióticos: semântico, sintático e pragmático. O plano semântico trabalha apenas com o significado da palavra, sem considerar o grupo de palavras ou o contexto em que se encontra. No plano sintático analisase a palavra em sua relação com outras palavras, ou seja, estuda-se a palavra dentro de um determinado período, bem como o sentido que adquire pelo uso de outras palavras do grupo. Já no plano pragmático faz-se o estudo do significado da palavra e do contexto em que a mesma se encontra e que, por sua vez, pode causar a transformação da análise isolada da palavra nos dois outros planos. Neste estudo, buscou-se analisar o texto constitucional com base no plano pragmático.

A interpretação pragmática baseia-se, segundo Ross (2003), "na suposição de que o legislador quis sancionar disposições que, em seus efeitos práticos, se harmonizassem com as exigências, valorações ou atitudes que presumivelmente gravitavam em torno dele" ( $p$. 175). No caso em questão, fez-se uso dessa interpretação para a resolução das indagações sobre os paradigmas ambientais adotados na Constituição Federal de 1988. Assim, foram criadas unidades de registro e contexto e estabelecidas às regras de classificação nos três paradigmas. A busca por reconhecer os paradigmas ambientais presentes no artigo 225 da 
Constituição Federal foi norteada, principalmente, pela ideia central contida nessas perspectivas: os paradigmas antropocêntrico e ecocêntrico pressupõem a existência de uma separação entre homem e natureza, sendo que o antropocentrismo vê a natureza subordinada ao homem e o ecocentrismo vê o homem subordinado à natureza; já o paradigma da sustentabilidade-centrismo vê a natureza e o homem como integrados e mutuamente dependentes. Por fim, o tratamento dos resultados e suas discussões envolveram tanto uma descrição analítica como algumas inferências sobre os paradigmas que se manifestaram no processo.

\section{Análise e Discussão dos Resultados}

A análise do artigo 225 da Constituição Brasileira partiu de sua fragmentação em 26 trechos principais, que foram classificados em umas das três categorias pré-estabelecidas: antropocentrismo, ecocentrismo e sustentabilidade-centrismo. Deles, 11 tiveram um viés predominantemente antropocêntrico, 3 foram ecocêntricos e 12 estavam mais próximos a uma visão centrada na sustentabilidade.

Dentre as unidades de análise que se aproximaram, predominantemente, de uma visão antropocêntrica, uma das que mais se destacaram, tanto pelo teor da afirmação quanto pela sua importância, dentro do texto da Constituição, foi o caput do artigo 225 que dispõe o seguinte:

Todos têm direito ao meio ambiente ecologicamente equilibrado, bem de uso comum do povo e essencial à sadia qualidade de vida, impondo-se ao Poder Público e à coletividade o dever de defendê-lo e preservá-lo para as presentes e futuras gerações (Constituição do Brasil, 1988).

Nesse trecho, são observadas quatro afirmações de cunho antropocêntrico. A primeira delas é que "todos têm direito ao meio ambiente ecologicamente equilibrado" (Constituição do Brasil, 1988). "Todos", nesse caso, se refere a todos os seres humanos, não incluindo, assim, nenhum outro ser que pudesse usufruir dessa situação. Seu cunho é antropocêntrico por tratar unicamente dos interesses humanos, ou seja, embora trate de maneira igualitária a humanidade, não considera que todos os outros seres também necessitem de condições adequadas para seu desenvolvimento. De maneira similar, a segunda afirmação, "bem de uso comum do povo" (Constituição do Brasil, 1988), também destaca o uso humano do ambiente como objeto de proteção do Poder Público. Além disso, há predominância de uma visão utilitarista do ambiente, visto que foca apenas no valor de uso que ele possa possuir, excluindo, nesse trecho, o valor de não-uso que se pudesse atribuir a ele. Assim, posicionase de modo que os interesses humanos sejam privilegiados, pois seriam estes os únicos a ter direitos sobre o ambiente, na forma de um bem comum. 
A terceira afirmação se refere ao ambiente como "essencial à sadia qualidade de vida" (Constituição do Brasil, 1988). Nesse caso, assim como na primeira afirmação, a vida a qual o texto se refere é a vida humana. Assim, tem-se a forma clássica de antropocentrismo, na qual o ambiente deve ser protegido e preservado, mas apenas por atender às necessidades e interesses humanos.

Por fim, afirma-se que sua preservação é necessária "para as presentes e futuras gerações" (Constituição do Brasil, 1988). A preocupação com as gerações futuras é expressa, o que remete ao conceito de desenvolvimento sustentável, elaborado pela Comissão Mundial de Meio Ambiente e Desenvolvimento [CMMAD] (1991), que o conceitua como "aquele que atende às necessidades do presente sem comprometer a possibilidade de as gerações futuras atenderem às suas próprias necessidades" (p. 46). Essa preocupação é relevante por considerar os interesses e necessidades daquelas gerações que, até então, não estariam envolvidos nas discussões sobre o uso da natureza e seus bens. Contudo, enquanto a CMMA (1991) estaria tornando tal interesse relevante ao discutir o desenvolvimento e as bases sobre as quais ele deveria ser obtido, a Constituição Brasileira se refere a este para discutir o direito ao meio ambiente. Embora se reconheça o esforço em se garantir os direitos de uso das gerações humanas que ainda estão por vir e, por isso, não poderiam requerer tais direitos, considera-se que faltou, no caput, buscar abranger os direitos que os seres não humanos teriam sobre o ambiente.

O primeiro parágrafo do artigo 225, que trata das incumbências do Poder Público para garantir o direito ao meio ambiente (Constituição do Brasil, 1988), apesar de ser influenciado pela sustentabilidade-centrismo, tem também características que remetem ao antropocentrismo e ao ecocentrismo. No caso do antropocentrismo, essa influência pode ser percebida em alguns trechos. No inciso II, diz-se que o Poder Público seria responsável por "preservar a diversidade e a integridade do patrimônio genético do País" (Constituição do Brasil, 1988) e, ainda "fiscalizar as entidades dedicadas à pesquisa e manipulação de material genético" (Constituição do Brasil, 1988). Nesses dois trechos pode-se observar que o ambiente é visto de uma maneira restrita, uma vez que o termo "patrimônio" remete a uma ideia de mensuração do acervo genético, assim como as pesquisas e manipulações envolvendo esse material é feita, de forma predominante, para benefício humano. Também o termo "material" pode ser visto como limitado, uma vez que determinado bioma, como um todo, envolve processos sinérgicos não totalmente explicáveis e mensuráveis em termos materiais.

Reforçando o viés antropocêntrico, no inciso V, afirma-se que o Poder Público deve "controlar a produção, a comercialização e o emprego de técnicas, métodos e substâncias que comportem risco para a vida, a qualidade de vida e o meio ambiente" (Constituição do Brasil, 1988, grifo nosso). Em destaque, temos duas características do antropocentrismo: a primeira se evidencia quando se trata de controlar processos e substâncias que possam ameaçar a vida, o que deixa implícito que se trata da vida humana, isolada e acima de qualquer outra forma de vida; a segunda se refere à qualidade de vida que, também implicitamente, se refere à qualidade da vida humana. Nesses dois casos, evidencia-se que o que se pretende preservar é a vida humana e sua qualidade. Isso fica evidente quando se observa o terceiro grifo do trecho, que se refere ao meio ambiente. Esse último fator poderia 
ser entendido como uma maneira de se referir ao todo, seres humanos, não-humanos e seu ambiente. Contudo, o fato de separar os homens do meio ambiente dá a entender a natureza reduzida a condição de objeto (BENJAMIN, 2011), posta à disposição daqueles.

A visão ecocêntrica é reforçada no inciso VII do primeiro parágrafo, que traz três fragmentos que se aproximam dessa visão, além de um fragmento no qual há traços antropocêntricos. $O$ trecho trata da obrigatoriedade do Poder Público de "proteger a fauna e a flora" (Constituição do Brasil, 1988) e permite a seguinte reflexão: se caberia ao Poder Público proteger apenas o conjunto de animais, incluindo talvez os seres humanos, e de plantas, quem se responsabilizaria pelos demais seres vivos que compõem a biota, como os vírus, bactérias ou fungos? Apesar dos traços ecocêntricos, por reforçar a separação entre homens e todos os outros seres, trata-se de um ecocentrismo que podemos chamar de individualista, pois não considera as espécies vivas como um todo, mas apenas as vegetais e animais. Há ainda outros trechos, neste inciso, que promovem certa separação entre os seres que compõem a biota, como na referência à extinção das espécies, por se tratar apenas de espécies animais e vegetais, e a submissão de animais a crueldade, por, novamente, dissociar os seres animais de todos os outros vivos. Porém, o viés antropocêntrico é novamente observado quando se associa a proteção da fauna e flora às suas "funções ecológicas" (Constituição do Brasil, 1988). O termo "função" associa a existência dos seres animais e vegetais ao cumprimento de um determinado papel. Neste caso, esse papel parece estar muito mais associado aos interesses humanos do que ao funcionamento do bioma como um todo, dando um enfoque utilitarista a esse inciso, embora deva-se reconhecer que as funções ecológicas, quando desvinculadas de seu caráter utilitarista, possui viés ecocêntrico.

Já no terceiro parágrafo do artigo 225, que trata da responsabilidade jurídica imputadas àqueles que causarem danos ambientais, por meio de sanções civis, penais ou administrativas, que poderiam reparar ou reverter um dano causado. Contudo, se sabe que a maior parte dos recursos naturais utilizados pela humanidade é esgotável e que os bens naturais têm uma marcante característica de irreprodutibilidade. Assim, apesar de o constituinte impor sanções na esfera jurídica no intuito de coibir o dano, uma vez este causado, apenas em situações muito específicas e restritas seria possível a reparação. Considerar o meio ambiente como tangível e mensurável, a ponto de considerar que os danos a ele possam ser reparados, é uma visão reducionista, um dos pressupostos básicos do antropocentrismo.

Logo após pressupor a possibilidade de reparar danos causados ao ambiente, afirmase, no parágrafo quarto, que "A Floresta Amazônica brasileira, a Mata Atlântica, a Serra do Mar, o Pantanal Mato-Grossense e a Zona Costeira são patrimônio nacional [...]" (Constituição do Brasil, 1988) e, portanto, deveriam ser protegidos. Ao se identificar espaços que merecem tratamento especial, o constituinte, implicitamente, reconhece a impossibilidade de reparar ou reverter os danos ambientais, pois não haveria necessidade de se preservar nenhum bioma específico se fosse possível recuperá-lo ou reproduzi-lo. Identifica-se nesse trecho o viés ecocentrista individualista, ao se promover a proteção com status constitucional a apenas algumas das macrorregiões do país

Ainda no parágrafo quarto, é retomada a ideia do uso humano dos bens ambientais, 
quando se acrescenta que a utilização dos biomas previstos deve assegurar "a preservação do meio ambiente, inclusive quanto ao uso dos recursos naturais" (Constituição do Brasil, 1988). Por duas vezes, o utilitarismo é ressaltado no parágrafo: quando se trata da utilização dos biomas e quando se trata dos recursos naturais nele contidos. Assim, novamente, é reforçado o viés antropocêntrico, quando se vincula a preservação ambiental ao uso humano, sendo, neste caso, amenizado pelo uso da expressão "inclusive". Assim, nota-se, em diversos trechos do artigo 225 da Constituição Brasileira, que o paradigma antropocêntrico prevaleceu, reforçando, principalmente, seus pressupostos de separação entre seres humanos e natureza, superioridade humana sobre todos os demais seres vivos, valorização da visão utilitarista do meio ambiente e preservação do ambiente apenas na medida em que seja útil aos seres humanos.

Contudo, em vários trechos, pode-se observar influência do paradigma centrado na sustentabilidade, que tem como ponto central uma maior integração entre homem e natureza, de modo que a responsabilidade do Poder Público seja com o ambiente como um todo, e não apenas com os seres humanos e os usos que eles possam fazer do meio ambiente. No caput do artigo 225 da Constituição Brasileira, isso se torna evidente quando afirma que é atribuído "ao Poder Público e à coletividade o dever de defendê-lo e preservá-lo" (Constituição do Brasil, 1988). Nesse ponto, pode-se observar que o ambiente é tratado de maneira mais integrada, envolvendo a biota como um todo, embora tenha, nesse mesmo enunciado, alguns vieses antropocêntricos, como já discutido.

Outros pontos, nos quais a predominância é de uma visão mais voltada para a sustentabilidade, encontram-se no parágrafo primeiro, que aponta, entre incumbências do Poder Público, a de "preservar e restaurar os processos ecológicos essenciais" e "prover o manejo ecológico das espécies e ecossistemas" (Constituição do Brasil, 1988). Tanto no termo "processo ecológico" como em "ecossistema", observa-se uma visão mais integracionista do ambiente, contrapondo-se às visões reducionistas antropocêntricas, que tratam apenas aspectos do ambiente que possam ter interesse humano, ou, ainda, parcelas específicas da biota. Assim, o trecho não se restringe apenas à parcela do ambiente que tem valor para a humanidade e reconhece que o meio ambiente seja possuidor de valor intrínseco.

No terceiro inciso do parágrafo primeiro, tem-se que o Poder Público deve "definir [...] espaços territoriais e seus componentes a serem especialmente protegidos" (Constituição do Brasil, 1988) e que é "vedada qualquer utilização que comprometa a integridade dos atributos que justifiquem sua proteção" (Constituição do Brasil, 1988). Assim, tem-se que algumas áreas serão protegidas, mesmo que não haja um interesse econômico diretamente associado ao seu uso, ou que seja qualquer outro uso humano futuro que se pretende preservar, embora este possa vir a existir. Assim, há um estímulo à preservação ambiental, ainda que não relacionado aos interesses humanos.

A ideia de um maior controle sobre as intervenções feitas no ambiente está presente no inciso quarto do mesmo parágrafo. Nele, diz-seque cabe ao Poder Público "exigir, [...] para instalação de obra ou atividade potencialmente causadora de significativa degradação do meio ambiente, estudo prévio de impacto ambiental, a que se dará publicidade" (Constituição do Brasil, 1988). Embora hoje a mensuração dos impactos causados ao ambiente não seja 
precisa e abrangente o suficiente, e a ideia de que eles possam ser medidos é uma visão muito restrita do ambiente, é preciso levar em conta que não é real imaginar que o homem possa vir a extinguir sua intervenção na natureza, o que torna necessária alguma forma de conduzir tal intervenção. Os estudos de impacto ambiental podem representar um importante esforço na busca de se evidenciar os impactos que as diferentes atividades econômicas causam sobre o ambiente, o que pode auxiliar na escolha de locais mais adequados para se implantar certos empreendimentos. Ainda que não se possam prever todos os impactos causados, eles vão buscar envolver tanto os que atingem as populações locais como aqueles sobre o ambiente como um todo.

Também a promoção da "educação ambiental em todos os níveis de ensino" (Constituição do Brasil, 1988), assim como a "conscientização pública para a preservação do meio ambiente" (Constituição do Brasil, 1988), previstos no inciso Vl do parágrafo primeiro, são medidas que podem ser vistas como influenciadas pela perspectiva da sustentabilidade, pois elas ajudam a melhorar a compreensão sobre a interação entre a humanidade e o ambiente, assim como a integração entre estes. A educação ambiental é uma das formas mais importantes de se alterar a maneira como a humanidade vê a natureza, unicamente como provedora de bens para seu uso e local para eliminação de resíduos. Alterar tal quadro e tornar a relação com a natureza mais harmônica depende de uma alteração no paradigma predominantemente compartilhado. Contudo, dependendo do enfoque adotado nas atividades de educação ambiental, essas podem assumir caráter antropocêntrico.

No parágrafo segundo do artigo 225 afirma-se que "aquele que explorar recursos minerais fica obrigado a recuperar o meio ambiente degradado" (Constituição do Brasil, 1988) colocando-se a obrigatoriedade de uma compensação ambiental pelo dano causado pela atividade mineral. Embora não seja possível recuperar de maneira total nenhum ambiente, pode-se considerar que tal medida é uma das poucas cabíveis no caso da exploração mineral, visto que a humanidade utiliza amplamente tais recursos.

Além disso, o parágrafo terceiro diz que "as condutas e atividades consideradas lesivas ao meio ambiente sujeitarão os indivíduos [...] a sanções penais e administrativas, independentemente da obrigação de reparar os danos causados" (Constituição do Brasil, 1988). Assim, em situações nas quais são causados danos ao ambiente, incluindo a atividade mineradora, são previstas duas compensações. A primeira diz respeito às sanções civis, penais e administrativas, no caso de danos ambientais. Tal punição pode ser considerada um desincentivo à degradação do ambiente, de modo que se estimule a busca por evitar tal dano. A segunda, de cunho mais antropocêntrico, trata da obrigatoriedade de reparação do dano. Apesar da impossibilidade de se reparar tal dano, como já foi discutido, essa pode ser vista como uma importante medida para tentar reduzir os danos causados ao ambiente e buscar se recuperar, ainda que não completamente, os locais nos quais foram causados algum dano.

Outro trecho que teve a sustentabilidade das atividades humanas como premissa foi o trecho do parágrafo quarto que estabeleceu que a utilização de algumas áreas tomadas como patrimônio nacional somente poderá ser feita "dentro de condições que assegurem a preservação do meio ambiente" (Constituição do Brasil, 1988). Embora tal parágrafo tenha restringido a apenas alguns biomas essas condições, sua redação é influenciada pela 
perspectiva da sustentabilidade, por prever que o uso dessas áreas será feita de modo a não degradar o ambiente. Como não se especificou o que exatamente se está considerando como passível de preservação, pode-se considerar que se deve considerar o ambiente como um todo, o que envolve toda a biota.

De maneira similar, o parágrafo quinto define que "são indisponíveis as terras devolutas ou arrecadadas pelo Estado, por ações discriminatórias, necessárias à proteção dos ecossistemas naturais" (Constituição do Brasil, 1988). Dessa forma, possibilita-se a criação e a preservação de áreas nas quais o ambiente possa ser protegido de forma integrada.

\section{Considerações Finais}

No presente artigo teve-se o objetivo de analisar o conteúdo do artigo 225 da Constituição Federal de 1988 sob a luz dos paradigmas ambientais do antropocentrismo, ecocentrismo e sustentabilidade-centrismo. Considerou-se que o processo de formulação da Constituição, bem como das outras espécies normativas que integram o ordenamento jurídico, é fortemente influenciado pelo sistema de crenças compartilhadas pelos indivíduos, constituindo os paradigmas que vão legitimar nossas ações e delimitar nossa visão de mundo. Para fins de analisar a visão que se compartilha do ambiente, o antropocentrismo, que considera a preservação dos recursos naturais necessária apenas na medida em que atenda às necessidades humanas, é visto como oposto ao ecocentrismo, que considera que a natureza possui valor intrínseco, que vai além daquele associado à utilidade humana. Em oposição a essa separação entre homem e natureza, se posiciona a sustentabilidadecentrismo, que busca integrar esses entes, considerando-os indissociáveis no tratamento do ambiente.

$\mathrm{Na}$ análise, em que se utilizou uma interpretação pragmática, foram separados 26 trechos dos quais 11 tiveram um viés predominantemente antropocêntrico, 3 foram ecocêntricos e 12 centrados na sustentabilidade. Observou-se que, embora valores antes rejeitados, como a preocupação com as gerações futuras e a criação de áreas de conservação, tenham sido incorporados ao texto constitucional, características que têm como fim a sustentabilidade, ainda se pode observar um viés fortemente antropocêntrico.

O viés antropocêntrico pode ser atribuído ao próprio perfil da Constituição, típico das cartas constitucionais criadas ou reformuladas após a Segunda Guerra Mundial, nas quais o princípio da dignidade da pessoa humana cumpre o papel de eixo central e orientador de todo o conteúdo a ser tratado em sede constitucional. Assim, embora a humanidade tenha papel central no texto constitucional, é preciso que se busque um posicionamento que garanta a preservação ambiental além daquela que tem como finalidade garantir o bem-estar humano. 
As análises realizadas nesse artigo se limitaram ao estudo dos paradigmas ambientais no artigo 225 da Constituição Federal por este conter as determinações que embasam a proteção ao meio ambiente em todo o ordenamento jurídico brasileiro. Ressalta-se que o artigo se restringiu à análise da filosofia ambiental (ética ambiental) que embasou a construção da norma e não na sua aplicação e interpretação pelos Tribunais. Esses, em especial o Superior Tribunal de Justiça (STJ), utilizam-se de princípios como a solidariedade, precaução, responsabilidade, mínimo existencial ecológico e proibição do retrocesso ecológico para a criação de uma "hermenêutica jurídica esverdeada" (LEITE, citado por BRASIL, 2010). Estudos posteriores podem se dedicar a verificação de uma possível mudança de paradigma ao se aplicar tais princípios.

Sugere-se também a análise da evolução da aplicação das normas ambientais ao longo dos anos, principalmente as mudanças na interpretação decorrentes de encontros internacionais como a Rio +20 , além de se dedicar a análise dos paradigmas ambientais de outros artigos constitucionais como os que determinam os princípios da ordem econômica brasileira ou os que traçam as diretrizes da política de desenvolvimento urbano, executada pelo Poder Público Municipal.

\section{Referências}

Albrecht, Don., Bultena, Gordon., Hoiberg, Eric., \& Nowak, Peter. (1982). Measuring environmental concern: the new environmental paradigm scale. The Journal of Environmental Education, 13(3), 39-42.

Bardin, Laurence. (1979). Análise de conteúdo (L. A. Reto \& A. Pinheiro, Trad.). São Paulo: Edições 70, Livraria Martins Fontes (Obra original publicada em 1977).

Benjamim, Antônio Herman. (2011). A natureza no direito brasileiro: coisa, sujeito ou nada disso. Nomos. Revista do Programa de Pós-Graduação em Direito da UFC, 31(1), 7996.

Burrell, Gibson., \& Morgan, Gareth. (1979). Sociological Paradigms and Organizational Analysis. London: Heinemann.

Campbell, Elisa. (1983). Beyond anthropocentrism. Journal of the History of the Behavioral Sciences, 19(1), 54-67.

Canotilho, José Joaquim Gomes. (1998). Direito constitucional e teoria da constituição. Lisboa: Almedina.

Cavalcanti, Clóvis. (1998). Sustentabilidade da economia: paradigmas alternativos de realização econômica. Em Clóvis Cavalcanti (Org.). Desenvolvimento e natureza: estudos para uma sociedade sustentável (2a ed). São Paulo: Cortez.

Comissão Mundial sobre Meio Ambiente e Desenvolvimento. (1991). Nossofuturo comum (2a ed.). Rio de Janeiro: FGV.

Coelho, Jorge Artur Peçanha de Miranda., Gouveia, Valdiney Veloso., Milfont, Taciano Lemos. (2006). Valores humanos como explicadores de atitudes ambientais e intenção de comportamento pró-ambiental. Psicologia em Estudo, 11(1), 199-207.

Constituição da República Federativa do Brasil de 1988 (48.ed.). (2013). São Paulo: Saraiva Derani, Cristiane (2008). Direito ambiental econômico (3.ed). São Paulo: Saraiva

Ferraz Júnior, Tércio Sampaio. (2003). Introdução ao estudo do direito: técnica, decisão e 
dominação. (4.ed.) São Paulo: Atlas.

Gladwin, Thomas Neil., Kennelly., James., \& Krause, Tara Shelomith (1995). Shifting paradigms for sustainable development: implications for management theory and research. Academy of Management Review, 20(4), p.874-907.

Göktürk Erek. (2009). What is "paradigm"?.Recuperado em 30 julho, 2009, de http://heim.ifi.uio.no/erek/essays/ paradigm.pdf

Gonçalves, Wilson José. (2002). Comunicação Jurídica: perspectiva da semiótica. Campo Grande: UCDB.

Kuhn, Thomas Samuel. (1996). The structure of scientific revolutions (3rd ed.) Chicago: University of Chicago.

Lenza, Pedro. (2010). Direito constitucional esquematizado (14. ed.). São Paulo: Saraiva.

Miralé, Edis. (2011). Direito do ambiente: doutrina-jurisprudência-glossário. (7. ed) São Paulo: Revista dos Tribunais.

Morin, Edgar. (1990). Introdução ao pensamento complexo (2. ed.) Lisboa: Piaget.

Pirages, Dennis Clark., \& Ehrlich, Paul Rauph (1974). Ark II: social response to environmental imperatives. San Francisco: Freeman.

Princípios de interpretação que ajudam o STJ a fundamentar decisões na área ambiental (2010). Superior Tribunal de Justiça. Disponível na internet em: http://www.stj.jus.br/portal_stj/publicacao/engine.wsp?tmp.area=398\&tmp.texto=9748 3 [Data de acesso: 06 dez.2013]

Redclift, Michael. (2005). Sustainable development (1987-2005): an oxymoron comes of age. Sustainable Development, 13(4), 212-227.

Rees, William. (2003). Economic development and environmental protection: an ecological economics perspective. Environmental Monitoring and Assessment, 86(1-2), 29-45.

Rohde, Geraldo Mário. (1998). Mudanças de paradigma e desenvolvimento sustentado. Em Clóvis Cavalcanti (Org.). Desenvolvimento e natureza: estudos para uma sociedade sustentável (2. ed.) São Paulo: Cortez.

Ross, Alf; (2003). Direito e justiça (E, Bini, Trad). Bauru: Edipro (Obra original publicada em 1953).

Silva, José Afonso da. (2009). Direito constitucional ambiental. (7.ed.) São Paulo: Malheiros.

Recebido em 21/09/2012

Revisado em 07/01/2012

Aceito 23/01/2013 